\title{
Disidencias: crítica del presente y crítica del lenguaje en la poesía española actual
}

\author{
José Luis Gómez Toré
}

\begin{abstract}
El recuerdo de la poesía social de posguerra y su desigual calidad ha podido generar en la poesía española cierta prevención frente a lo político. Sin embargo, determinadas circunstancias (el I5-M y el movimiento de los indignados, una importante crisis económica...) así como el trabajo de escritores como Enrique Falcón, Antonio Méndez Rubio o Julieta Valero ha reavivado la posibilidad de que la lírica se articule también como un discurso crítico. Dichas prácticas poéticas no siempre se centran en la denuncia explícita, sino que frecuentemente tienden a interrogarse sobre el papel del propio lenguaje en la construcción de lo colectivo.
\end{abstract}

Keywords: Poesía española, política, crítica, sociedad, lenguaje

Puedo equivocarme, pero me da la impresión de que, al abordar la presencia de lo político en la poesía española, no se ha disipado del todo la sospecha que acompañó a la llamada poesía social, con todos los fantasmas que dicha expresión convoca: la renuncia a la tensión lingüística y a las exigencias estéticas en aras de una mayor comunicabilidad, cierto tono profético a menudo impostado, una apuesta ingenua por la poesía temática (como si la sola elección de unos temas concretos convirtiera al poema en una herramienta de transformación social). Si comparamos, de hecho, la poesía escrita en este lado del Atlántico con la de los autores hispanoamericanos, constatamos que estos han tenido, por lo general, menos dificultades para aunar contenidos de alta carga crítica, incluso revolucionaria, con un lenguaje igualmente radical, que no abandona la herencia de las vanguardias (lejos de esa idea tan dañina que Ortega y Gasset difundió entre nosotros del vanguardismo como sinónimo de puro juego intelectual). Y ello, a pesar de que no faltan referencias españolas, por más que esa herencia no haya sido del todo aprovechada. Pienso en libros como El inocente y Presentación y memorial para un monumento de José Ángel Valente, Descripción de la mentira de Antonio Gamoneda o, para remontarnos aun más allá, Poeta en Nueva York de Federico García Lorca. Títulos en los que la denuncia no siempre es explícita, pero que dejan entrever que no es incompatible la interrogación hacia el propio lenguaje con un cuestionamiento profundo de las estructuras de poder.

Si muchos vieron en la poesía social una obligada estética de combate, explicable solo por el contexto histórico del franquismo, no es de extrañar que el fin del régimen y la evolución posterior de la sociedad española ha- 
yan llevado a la convicción contraria. Como si, desaparecido el franquismo, los escritores pudieran, por fin, descansar en paz abandonando una penosa tarea que, en el fondo, muchos sentían como ajena a la poesía. En la España del despegue económico, de la rápida modernización, de la integración en Europa, solo unos pocos aguafiestas parecían sentirse obligados a adoptar una actitud de desconfianza. A ello, se sumó, claro está, el desencanto ante los grandes relatos de la modernidad (entre los que cabe contar, desde luego, el sueño revolucionario) que forma parte del paisaje de lo que se ha llamado la condición posmoderna.

Cabe preguntarse, sin embargo, si la penosa crisis económica y la creciente desigualdad, así como la incidencia de movimientos populares como el I5-M, no pueden estar abriendo de nuevo la brecha para el debate en esos «tiempos de la nueva austeridad», a los que se alude en un poema de Jordi Doce ${ }^{\mathrm{I}}$. Lo político cobra una urgencia visible en versos como estos: «mientras fuera el barrio / los desahucios / los señalamientos / las primeras restituciones de un mundo/ que lleva dentro de sí el intento de otro mundo $»^{2}$. En ese sentido, me parece significativa la propuesta que ofrece un libro colectivo, de reciente aparición, Marca(da) España ${ }^{3}$. En él, más de cincuenta poetas dialogan con las imágenes tomadas por el fotógrafo alemán Reiner Wandler: fotografías que retratan la pobreza, la exclusión social, pero también la rebeldía (con un especial protagonismo del movimiento de los indignados del I5-M). No me parece secundario el hecho de que, entre los participantes, se cuentan no solo poetas que se han ido dando a conocer en las últimas décadas como Óscar Curieses, Luis Luna, Laura Casielles... sino asimismo autores de larga trayectoria como Félix Grande o Antonio Gamoneda. Y es que, si bien mi trabajo se centra en poetas nacidos a partir de 1965 , no se puede olvidar la huella que en estos escritores han dejado voces como la de Jorge Riechmann o Juan Carlos Mestre, también incluidos en Marca(da) España. Como ejemplo significativo, Miguel Casado, otro de los nombres pertenecientes a generaciones anteriores que encontramos en el volumen, es autor de El sentimiento de la vista, un libro publicado en 2015 que incluye varios poemas en torno a nombres de plazas que evocan resistencias frente al poder (Tahrir, Syntagma, Tiananmen). Con todo, lo más sugerente de este poemario quizá resida en la manera en que la experiencia individual se funde sin subrayados de ningún tipo con la experiencia colectiva. El yo poético es así un yo histórico, cuyas reflexiones son tal vez las que se harían mu-

I Jordi Doce, No estábamos allí, Valencia, Pre-Textos, 20I6, p. I7.

2 Ernesto García López, Todo está en todo, Madrid, Amargord, 2016, p.94.

3 VV.AA., Marca(da) España. Retrato poético de una sociedad en crisis, Madrid, Amargord, 2014. El título juega de manera irónica con la obsesión por la llamada Marca España en el discurso oficial, empeñado en vender cierta imagen del país (y que ha llevado incluso a crear una oficina gubernamental: el Alto Comisionado para la Marca España). 
chos de sus contemporáneos si las pudiesen expresar de manera tan nítida: «quizá mis emociones / empiecen a ser cosa de la edad, / pero ese ejercicio de sumar plazas/y fracasos parece al menos una forma / de las que elige el pensamiento / para hacerse a sí mismo» ${ }^{4}$.

Si solo una mirada ingenua puede considerar que la subjetividad se construye al margen de lo social, ni las ideas ni los sentimientos, como sugieren los versos de Casado, son el fruto de una conciencia edénica. Pensamos y sentimos desde las líneas de fuerza que atraviesan nuestra realidad, en el entramado lingüístico y simbólico que nos constituye como individuos de una determinada época. Así, la poesía crítica puede ser una poesía abiertamente de denuncia, permeable a los acontecimientos históricos del momento, pero también puede ejercerse la disidencia desde una crítica al propio funcionamiento del lenguaje como arma de guerra e instrumento de consenso social (significativamente, en Marca(da) España encontramos ambas direcciones poéticas). En este breve ensayo va a ser esta segunda posición en la que nos centremos (entendiendo que ambas orientaciones no son excluyentes, sino que, en todo caso, constituyen coordenadas entre las que se mueve toda poesía crítica, que puede escorar hacia uno u otro polo). La escritura que quiere ser al mismo tiempo crítica del lenguaje y crítica del presente parece hacer suya implícitamente la tesis defendida por Rancière, uno de los pensadores contemporáneos que más han reflexionado sobre estética y política:

El arte no es político, en primer lugar, por los mensajes y los sentimientos que transmite acerca del orden del mundo. No es político, tampoco, por la manera en que representa las estructuras de la sociedad, los conflictos o las identidades de los grupos sociales. Es político por la misma distancia que toma con respecto a sus funciones, por la clase de tiempo y espacio que instituye, por la manera en que recorta este tiempo y puebla este espacio 5 .

La intersección entre arte y política tiene que ver, por tanto, con cómo se articulan los modos de representación de la realidad (una realidad que no está dada, sino que es siempre, como reza el título de un libro de Luis Bagué, Página en construcción). También con la necesidad de interrogase sobre quién decide lo que se puede decir y lo que no, qué reglas implícitas rigen el universo del discurso. En buena medida, se trata de asumir el concepto de biopolítica, esbozado por Benjamin y desarrollado por pensadores como Agamben y Foucault. Y es que los mecanismos de control no son ya necesa-

4 Miguel Casado, El sentimiento de la vista, Barcelona, Tusquets, 2015, p. 87.

5 Jacques Rancière, El malestar en la estética. Madrid, Clave Intelectual, 20I2, p. 33. 
riamente represivos en las democracias liberales, sino que operan de modo más efectivo en la constitución de cada sujeto. El deseo se ha vuelto así político (si es que alguna vez dejó de serlo). Y ese no es, en absoluto, un terreno ajeno al arte. Así, por ejemplo, temas clásicos de la poesía lírica como pueden ser el amor y el erotismo pueden convertirse en punto de partida para preguntar cómo se construyen nuestras identidades (masculina, femenina, heterosexual, gay...) desde una cultura patriarcal todavía operante, aunque en buena medida invisibilizada por el discurso de lo políticamente correcto (de ahí el interés de la exploración de la sexualidad en escrituras como la de Miriam Reyes).

Ello lleva necesariamente a replantear la consideración del arte político como un arte de denuncia, o solo de denuncia. El mero testimonio corre el riesgo de sumarse sin más al ruido informativo que nos proporciona nuestra dosis diaria de catástrofes, dosis que, lejos de despertar el deseo de acción, parece actuar como una suerte de sucedáneo de la política, incluso como un alimento narcisista que más bien paraliza la intervención en la realidad. Eso sin contar con la dificultad de dar testimonio, con el riesgo de suplantar la voz de la víctima (una cuestión sobre la que se ha reflexionado, y mucho, en el después de Auschwitz del que formamos parte). Si la propaganda se ha hecho sospechosa (no solo por el uso de ella que han hecho el fascismo y los regímenes de cuño estalinista, sino también por su utilización como mecanismo de legitimación y consenso en el capitalismo avanzado), el arte no puede asumir sin incomodidad su conversión en pura retórica publicitaria. De ahí que, como afirme Enrique Falcón, la poesía política no tenga por qué ser transparente, si por transparencia se entiende la falsa imagen de una comunicación no distorsionada, en la que no existen interlocutores en una posición de control o privilegio. Una utopía que puede valer como ideal regulativo en las propuestas éticas de un Habermas o Apel, pero que, cuando se presenta como realmente existente, no deja de mostrar una profunda carga ideológica, esto es, encubridora de la realidad:

Un poema político no tiene por qué ser «transparente».

No es necesariamente lo transparente donde siempre acaece una comunicación.

No siempre en lo ya conocido se producen los encuentros.

Y no necesariamente en la claridad, el abrazo y la protesta ${ }^{6}$.

Enrique Falcón, el autor de estas líneas, es un buen ejemplo de cómo la disidencia política es compatible con un trabajo exigente con el material lingüístico. El estilo alucinado, a menudo expresionista de Falcón, con un tono

6 Enrique Falcón, Taberna roja, Tegueste (Tenerife), Baile del Sol, 2008, pp. 83-84. 
profético que debe tanto a la Biblia como a las vanguardias, quiere ser en sí mismo testimonio de una realidad rota, fragmentada, en la que el duelo por las víctimas es el primer paso para levantar, contra toda evidencia, el imperativo ético de la esperanza. Como escribe García-Teresa, «Enrique Falcón pone en práctica una poesía de fractura a todos los niveles, en lo sintáctico y también en lo semántico»7. Si, como venimos insistiendo, es la construcción de la subjetividad el campo de batalla en el que la lírica puede cumplir un papel que le es propio, en la escritura de Falcón destaca un elemento básico de la identidad como es el cuerpo, cuerpo mimado, idealizado en las imágenes publicitarias de nuestro presente, pero que es asimismo el objeto potencial de todas las violencias (y que puede revelarse, al mismo tiempo, como un cuerpo que actúa, que deja su huella en lo real):
regreso con la arruga y la boca calentada
en palabras enroscándose a la encía,
y en el diente perforado,
por todo aquello que quisimos hace tiempo
y que ahora es hombro, muslo, tendón herido,
o seno o labio o clavícula deshecha ${ }^{8}$.

Por otro lado, hay que señalar la importancia que adquieren en un libro como La marcha de los I50.000.00o las notas al margen de la página, con referencia a citas, acontecimientos o datos a los que se alude en el cuerpo del poema. El peso de estas anotaciones hace que, más que un paratexto, podamos considerarlas un intertexto, a través del cual se establece una llamativa tensión entre lo documental y lo profético, entre la denuncia directa, testimonial, y el poema propiamente dicho. De esta manera, quizá sin pretenderlo, Falcón nos sitúa ante la insuficiencia del documento y, al mismo tiempo, ante la resistencia de la palabra poética a convertirse en mera transmisora de información, en puro instrumento de denuncia y de propaganda política.

Dicha resistencia resulta más que evidente en otro escritor, Antonio Méndez Rubio, como el citado, miembro, en sus inicios, del colectivo crítico Alicia bajo cero (si bien Falcón abandonó el grupo ya en 1994). En Méndez Rubio se aúnan práctica poética y teórica para explorar los límites del decir,

\footnotetext{
7 Alberto García-Teresa, Poesía de la conciencia crítica (I987-20II), Ciempozuelos (Madrid), Tierra de Nadie, 2013, p. 270. El voluminoso estudio de García-Teresa (que se complementa con una nutrida antología, Disidentes. Antología de poetas críticos españoles (I990-20I4), Torrejón de Ardoz (Madrid), La oveja roja, 20I4) muestra, a las claras, cómo esa poesía de denuncia no ha desaparecido en absoluto de la lírica española. Si bien García-Teresa centra más su estudio en autores con contenidos abiertamente políticos, no faltan tampoco alusiones a esa otra forma de crítica desde dentro del lenguaje que hemos señalado.

8 Enrique Falcón, La marcha de los 150.000 .000 , s.l., Eclipsados, 2009, p. 55.
} 
desde un cuestionamiento profundo de las exigencias de comunicación que se plantean desde cierta poesía social, exigencias, por cierto, del todo coincidentes con la ideología del capitalismo avanzado, de una sociedad la que la transparencia a toda costa es la otra cara de un creciente control sobre los individuos.

La escritura de Méndez Rubio se mueve así en un terreno minado, el del sentido. Para el poeta, la exigencia de una significación evidente se vuelve harto sospechosa, en especial en la llamada sociedad de la información, uno de cuyos pilares económicos es, por cierto, y de forma creciente, el comercio de datos públicos y privados. Si la información así como la producción masiva de imágenes y relatos se convierten en elementos centrales del mercado, la poesía aparece más que nunca como un decir extraño, como un balbuceo inclasificable: «Así vas aprendiendo que en la carne / el fracaso te crece y te descrece / como la libertad. Como el sentido / se desprende a pedazos del poema»9. El reclamo de un significado unívoco busca normalizar la poesía, convertirla en un discurso aceptable. Sobre ello, y sobre el margen de disidencia que puede darse todavía en el arte, ha teorizado, en varios trabajos, el autor. El más reciente se titula Abierto por obras. Ensayos sobre poética y crisis, al que pertenece este fragmento:

[...] el lenguaje es visto aún como un sistema abstracto de signos en lugar de como una práctica dialógica e ideológica en conflicto [...]. Así, o bien se desconfía del lenguaje o bien (puede que a la vez) el discurso crítico se entrega al lenguaje como si este fuera un instrumento de mera transmisión, una superficie homogénea y unitaria, en lugar de un espacio estallado por miríadas de fuerzas que reflejan y a la vez interfieren en la producción de conciencia y realidad social. Se oye muy a menudo que el lenguaje coloquial podría sacar a la poesía del hermetismo, de la excesiva codificación, pero es más raro asistir a un cuestionamiento de las formas de codificación cristalizadas en el registro coloquial ${ }^{10}$.

En consecuencia, la crítica de Méndez Rubio se ejerce tanto sobre las inercias de las prácticas discursivas como en torno a la construcción del sujeto, cuestionando de paso la idea tradicional de la lírica como expresión de las propias emociones: «[...] la poesía más ingenua o inercial se entrega como pocos discursos y acciones a la hegemonía entre simpática y mesiánica del yo expresivo, del sujeto como autoimagen, del selfie» ${ }^{\mathrm{II}}$. Ello implica asimismo un rechazo de la estética realista, o mejor dicho, de una concepción

9 Antonio Méndez Rubio, Por más señas, Barcelona, DVD Ediciones, 2005, p. 56.

Io Antonio Méndez Rubio, Abierto por obras. Ensayos sobre poética y crisis, Madrid, Libros de la resistencia, 20I6, pp. 39-40.

II Antonio Méndez Rubio, op. cit., p. 2I. 
demasiado estrecha del realismo, y por ende, de lo real: «sí lo que no pasó / más duele / más espera / que lo que sí pasó / la realidad qué sabe» ${ }^{12}$. En el fondo, se trata, claro está, de no aceptar el consenso social sobre lo posible y lo imposible, de poner trabas al mecanismo básico de legitimación del poder que consiste en convertir lo histórico y contingente en necesario y natural.

En Julieta Valero se une también la resistencia a significar con un alejamiento de la poesía expresiva (por usar el término de Méndez Rubio) que exalta el yo y sus vivencias. Algo que se evidencia ya en el título de su último libro Que concierne, que parece una frase incompleta, tanto por la falta de antecedente del relativo «que» como por la omisión de un complemento personal que parecería exigir el verbo «concernir». Si el libro se titulara $L o$ que nos concierne o, incluso, Que nos concierne habríamos entrado de lleno en la retórica política. Sin embargo, la omisión de un pronombre de primera o segunda persona, convierte el título en algo extrañamente desasido, en una botella al mar (por utilizar la imagen celaniana) que no da por sabidos los lazos intersubjetivos, el contrato social. Es el lector el que tiene que decidir hasta qué punto le conciernen el conflicto y la esperanza, esperanza que apenas se atreve a insinuarse en el epígrafe del primer poema: «\#spanishrevolution» (incluido, por cierto, en Marca(da) España). La expresión por sí sola puede resultar tópica, cuando no, irritantemente ingenua, puesto que, por interesantes que hayan sido los procesos surgidos en torno al I5-M, no estamos desde luego, ni con el mayor voluntarismo, ante una «revolución». Sin embargo, en el libre movimiento del lenguaje del poema, la expresión conserva, como un débil aliento, su frágil carga utópica, como una posibilidad no cumplida, pero que existe como memoria, como lo que pudo llegar a ser y quiere todavía hacerse real.

Lo que acabamos de comentar nos sitúa en una de las líneas más interesantes de la poética de Valero. La resistencia a la significación, que antes emparentábamos con Méndez Rubio, recuerda en cierto modo a las tesis de Mario Montabetti, quien cifra la voluntad artística en el rechazo a convertir la obra en signo: «El signo destruye el sentido para fosilizar la significación, es decir, domestica una cadena de significantes atribuyéndoles la seguridad de un significado» ${ }^{13}$. No es momento ahora para analizar hasta qué punto es posible separar sin más sentido y significación, pero resulta evidente que la escritura de Julieta Valero rehúye la significación unívoca para abrirse a un sentido no cerrado. «Descontextualizada rindo más» ${ }^{4}$ afirma la autora con un rasgo de humor que constituye una de sus más eficaces estrategias discursivas. Esa descontextualización es la que pone en movimiento el sentido,

I2 Antonio Méndez Rubio, Nada y menos, Cáceres, Ediciones Liliputienses, 2015, p. 5I.

I3 Mario Montalbetti, Cualquier hombre es una isla. Ensayos y pretextos, Lima, Fondo de Cultura Económica, 20I4, p. 55.

I4 Julieta Valero, Que concierne, Madrid, Vaso Roto, 2015, p. 80. 
proceso por el cual fragmentos del lenguaje cotidiano adquieren un espesor sorprendente. $\mathrm{Y}$ es asimismo esa (relativa) descontextualización la que abre un espacio de libertad, que quiebra la determinación histórica. Hacia ello apunta la cita de Irène Nemirovsky que cierra el libro y que sirve para titular su última sección, «O 2052»: «2 de junio de 1942: no olvidar nunca que la guerra acabará y que toda la parte histórica palidecerá. Tratar de introducir el máximo de cosas, de debates... que puedan interesar a la gente en 1952 o 2052».

Es evidente la intencionalidad crítica e irónica de algunos pasajes («La ministra de Trabajo llora al anunciar las nuevas medidas» $\left.{ }^{16}\right)$. Con todo, tal vez la pregunta por lo político del libro no resida tanto en esas alusiones al presente como en los lazos que anudan lo personal y lo colectivo, de ahí la importancia de motivos como la infancia, el cuerpo o la maternidad. Acierta la también poeta María Salgado al señalar en el epílogo de Que concierne que «quizás es un libro sobre la reproducción de la vida en unas condiciones materiales muy localizadas» ${ }^{17}$. Por ello, un poema de amor a otra mujer puede tener un significado íntimo y a la vez político, desde la voluntad de abrir puentes, de defender el derecho de construir la propia existencia, de otorgar nuevos sentidos a palabras tan viejas como madre ofamilia: «seguirás de pie en nuestra cocina, escuchando a las cebollas, la frente perlada de generosidad y de viajes al centro de la Tierra. La mujer que le lee sus derechos a la belleza. Nuestro hijo ahí» ${ }^{18}$. Y ello implica también una batalla lingüística, que se da en «la transexual periferia del lenguaje $»^{19}$, en ese ámbito donde la escritura vuelve porosas, fluidas, las identidades, las consignas que nos hacen adoptar un rostro como propio. De ahí que la posibilidad de lo nuevo, que viene con el hijo, con la hija, pueda leerse también como un deber ético, como la invitación a explorar otros vínculos comunitarios. No todos los cambios se anuncian con grandes convulsiones («Las buenas noticias, en la mayoría de los casos, se dan en voz baja ${\aleph^{20}}^{\circ}$.

Si obras como la de Valero o Méndez Rubio nos sitúan ante la necesidad de no ceder a las inercias del discurso, otro tanto ocurre en Raúl Quinto, en cuyo poemario La flor de la tortura (donde, al igual que en Valero o en Falcón, el cuerpo constituye un motivo central) el lenguaje, y en especial el lenguaje poético, es puesto bajo sospecha: «Escribo que no hay nada / dentro de las palabras / como tampoco hay nada en las pupilas / del que observa la nie-

I5 Julieta Valero, op. cit., p. 83.

I6 Julieta Valero, op. cit., p. Io.

I7 Julieta Valero, op. cit., p. 93.

I8 Julieta Valero, op. cit., p. 56.

I9 Julieta Valero, op. cit., p. 2 I.

20 Ibidem. 
ve, // y, desde aquí, / desde este extremo de la niebla, / desobedezco» ${ }^{21}$. La ambigüedad es palpable: el lenguaje se muestra como un espejismo y, sin embargo, solo ese espejismo permite abrir un precario espacio de disidencia. En otro libro posterior, Ruido blanco, en el que se recrea un suceso real (el suicidio en directo de una presentadora de televisión), la inevitabilidad de la escritura se hace aún más evidente a la hora de poner coto a la invasión actual de las imágenes, que constituye un serio obstáculo para la distancia crítica:
Propongo un ejercicio: arrancar esta página del libro y aproximarla lentamente a la pantalla: las imágenes se desvanecen / a través del papel, y estas palabras transparentan su vacío ilegible ${ }^{22}$.

La violencia es una constante en la obra de Raúl Quinto. Esa violencia aparece mucho más matizada, en ocasiones casi invisible, en un libro como Reses de Esther Ramón. Sin subrayados de ningún tipo, pero desde una fascinante indagación en los vínculos entre lo humano y lo no humano, emerge de nuevo el enigma de la corporalidad, la seducción mítica que nos aparta del animal por miedo a ver en este un semejante: «Dadle un cuchillo al soldado hambriento. Mordisqueará las manzanas más jugosas: el costillar, las criadillas, los sesos. Con los hombres cayeron animales. Los cuartos traseros $»^{23}$. Si en Reses se deja entrever que la lógica sacrificial no ha desaparecido de nuestro imaginario colectivo (lo que la hace, por tanto, doblemente peligrosa), en Grisú, Ramón se muestra muy atenta a la memoria de las cosas, a las huellas que el trabajo ha dejado en la tierra, como si el mismo olvido cubriera tanto el mundo natural como a los seres humanos que arrastran una larga historia de heridas y derrotas: «con azadas / la abrimos / y manaron / panes duros / de colores / vivos como / las mantas /que cubren / los rostros / de los muertos / se borraron los dientes / y vino el hambre / de lamer piedras» ${ }^{24}$.

Ejemplos como el último nos muestran hasta qué punto no es preciso adoptar los modos de la poesía comprometida para hacerse cargo del presente, o, como en este último caso, del pasado. De ese pasado que no está hecho solo de lo que fue, sino también de lo que pudo ser. La memoria del

2I Raúl Quinto, La flor de la tortura, Sevilla, Renacimiento, 2008, p. 48.

22 Raúl Quinto, Ruido blanco, Córdoba, La bella Varsovia, 2012, p. 31.

23 Esther Ramón, Reses, Gijón, Trea, 2008, p. 20.

24 Esther Ramón, Grisú, Gijón, Trea, 2009, p. 29. 
dolor abre también una expectativa, se interroga sobre la posibilidad de escapar de la repetición, de los círculos míticos de la violencia. Por ello querría acabar este apresurado itinerario con un fragmento de un poemario reciente de Pilar Martín Gila, en el que la imagen de la cerillera de Andersen sirve para interrogarse sobre esa dolorosa carga del recuerdo, sobre la delgada línea que separa la pesadilla del despertar: «Si no muere de frío la cerillera, tendrá que incendiar todo lo que soñaba. Y ha crecido con ella. Si le quedan cerillas. No el baile de la pequeña llama. Sino el frío. Parece la hora, pero es solo frío» ${ }^{25}$.

25 Pilar Martín Gila, Otro año del mundo, Madrid, Ediciones La Palma, 20I4, p. 59. 